\title{
A CONCRETIZAÇÃO DO DANO AMBIENTAL E A TEORIA DA RESPONSABILIDADE OBJETIVA
}

\author{
Ana Augusta Rodrigues Westin Ebaid ${ }^{1}$
}

\author{
Rachel Lopes de Queiroz Chacur ${ }^{2}$
}

\section{Lucas Marcelo Galindo ${ }^{3}$}

RESUMO: A discussão se concentra em torno da questão do "dano ambiental", voltando atenção para o conceito de dano, buscando atribuir uma interpretação coerente, sempre observando as circunstâncias do caso concreto. A questão do dano ambiental, bem como a de seus impactos no meio ambiente trazem diversas consequências jurídicas, dentre elas, a responsabilização civil dos agentes deles causadores. Dentre as considerações jurídicas, serão analisados os dispositivos constitucionais que determinam a responsabilidade por danos causados ao meio ambiente, assim como os efeitos da lei 6.938 , de 31 de agosto de 1981, conhecida como Política Nacional do Meio Ambiente. O estudo pretende abordar o que a

\footnotetext{
${ }^{1}$ Mestre pelo Centro Universitário Eurípedes de Marilia - Univem. Docente do Núcleo de Pesquisa e Extensão da Universidade do Oeste Paulista, membro do grupo de estudo de direito ambiental da Universalidade do Oeste Paulista. E-mail. anaaugusta@unoeste.br.

${ }^{2}$ Mestre em Direito Processual Civil pela Universidade do Oeste Paulista - Unoeste. Docente na área de Direito Civil e Prática Jurídica da Universidade do Oeste Paulista, membro do grupo de estudo de direito ambiental da Universalidade do Oeste Paulista E-mail.rachel@unoeste.br.

${ }^{3}$ Discente do Curso de Direito da Universidade do Oeste Paulista - Unoeste, membro do grupo de estudos de direito ambiental da Universidade do Oeste Paulista, pesquisador da linha teórica: Sociedade e Meio Ambiente. E-mail.galindo.galingo@bol.com.br.
} 
doutrina jurídica atualmente entende por "dano ambiental", demonstrando que o dano causado ao meio ambiente precisa ser reparado ou compensado à sociedade. O levantamento bibliográfico e a análise acerca das principais abordagens jurídicas apontam que o dano ambiental, bem como o impacto sobre o meio ambiente devem ser minimizados na equação custo-benefício, visando ao desenvolvimento da sociedade de forma sustentável, social e economicamente equilibrada. A propósito, este é um dos maiores desafios que a sociedade enfrenta hoje, pois os expedientes jurídicos, apesar de necessários, não são suficientes para a devida proteção do ambiente. Assim, a necessidade da construção da consciência ecológica é questão estratégica para o desenvolvimento sustentável de qualquer sociedade.

Palavras-chave: Dano Ambiental, Responsabilidade Civil, Desenvolvimento Sustentável.

\section{INTRODUÇÃO}

Os estudos relacionados com a questão do dano ambiental, bem como a evolução jurídica do seu conceito vêm, a cada dia, ganhando mais projeção. A busca do conceito de dano ambiental exige considerações especialíssimas, que estão diretamente ligadas à questão da responsabilidade civil.

O presente estudo, objetiva tecer as principais abordagens doutrinárias a respeito do dano ambiental, avaliando a responsabilidade civil e seus principais elementos no direito brasileiro. A relevância do estudo está em pautar a importância da preservação do meio ambiente, respaldado no direito fundamental de proteção à vida em todas as suas formas.

A escolha do tema justifica-se, fruto da sua relevância, tendo em vista que o Direito Ambiental introduz uma série de novos conceitos e classificações que permitem uma melhor compreensão da ordem jurídica, buscando harmonizar as relações humanas e econômicas, voltadas à proteção e preservação do meio ambiente viabilizando o desenvolvimento sustentável.

Por tratar-se de matéria relativamente nova no direito brasileiro, a proteção ao meio ambiente, tem recebido os mais variados tratamentos legais. Portanto está adstrito aos 
princípios de direito ambiental, aos princípios gerais de direito, as regras de direito material e processual civil e especialmente das legislações ambientais.

A lei no 6.938 de 31 de agosto de 1981, conhecida como Política Nacional do Meio Ambiente, trata da responsabilidade civil objetiva do poluidor, obrigado, independentemente da existência de culpa, a indenizar ou reparar os danos causados ao meio ambiente e a terceiros, afetados por sua atividade. Para tanto, basta que se prove um nexo de causa e efeito, entre a atividade de alguém e a ocorrência do dano ambiental.

Nesta perspectiva, o estudo busca aprofunda-se, nos conceitos e entendimentos doutrinários, que permeiam as discussões sobre o dano ambiental, propondo medidas efetivas que buscam tutelar o meio ambiente. Dessa forma, o que se pretende é a apresentar a necessidade da construção da consciência ecológica por entender que os expedientes jurídicos apesar de necessários, não são suficientes para a devida proteção do meio ambiente.

\section{CONCEITO DE DANO E DANO AMBIENTAL}

O entendimento e a avaliação do que vem a ser dano são extremamente importante, para a compreensão do que venha a ser dano ambiental. Vale ressaltar-se, que as questões ligadas à responsabilidade civil estão diretamente ligadas à ocorrência de algum tipo de dano.

No dizer de Serpa Lopes: A noção de dano comporta dois elementos: $1^{\circ}$ elemento de fato - o prejuízo; $2^{\circ}$ elemento de direito - a violação ao direito, ou seja, a lesão jurídica. (1995, p. 222).

A moderna literatura jurídica tem encontrado dificuldades, para definir dano ambiental. A busca de um conceito de dano ambiental exige considerações especialíssimas, que, em última instância, estão vinculadas ao conceito de prejuízo.

Conforme menciona Édis Milaré (2000, p. 334), 
Neste mesmo sentido, o autor Paulo de Bessa Antunes aponta que o conceito de meio ambiente é cultural. "É a ação criativa do ser humano que vai determinar aquilo que deve e o que não deve ser entendido como meio ambiente" (1999, p. 149).

Para esse autor, o meio ambiente é um bem jurídico autônomo e unitário, que não se confunde com os diversos bens jurídicos que o integram.

\begin{abstract}
O bem jurídico meio ambiente não é um simples somatório de flora e fauna, de recursos hídricos e recursos minerais. O bem jurídico ambiente resulta da supressão de todos os componentes que, isoladamente, podem ser identificados, tais como florestas, animais, ar etc. Esse conjunto de bens adquire uma particularidade jurídica que é derivada da própria integração ecológica de seus elementos componentes (1999, p. 149).
\end{abstract}

Nesta ordem de ideias, Fernando Baum Salomon, valendo-se da lição de Ernesto e Cesário Brigante, anota:

\begin{abstract}
A noção de "bem ambiental" não é tipicamente jurídica, sendo uma associação de linguagem sociológica, urbanística, arquitetônica; e, além disso, recorrendo, com frequência a muitas leis, sobretudo regionais, não foi possível elaborar uma noção unitária de ambiente, que não seja, de tal forma ampla de ser escassamente significativa. Tem-se, como exemplo, a definição de proposta do Conselho Internacional de Língua Francesa, segundo a qual o ambiente (environment) é um conjunto, em um dado momento, dos agentes físicos, químicos, biológicos e dos fatores sociais, suscetíveis de terem um efeito direto ou indireto, imediato ou não, sobre os seres viventes e a atividade humana (2004. p. 231).
\end{abstract}

Fernando Baum Salomon acrescenta, ainda:

Que este bem tem relação direita com a digna condição humana de ver preservado o seu habitat,ou seja, que o ser humano, dentro de uma ideia antropocêntrica alargada, é o destinatário de todo este extenso conceito de ambiente, ou melhor dizendo, bem ambiental (2004. p. 232).

A fruição do bem jurídico meio ambiente é sempre de todos, ou seja, é um direito fundamental do ser humano. Em razão de sua relevância, o bem jurídico ambiente encontra tutela em institutos de direito público e direito privado.

O dano público contra o meio ambiente, o "bem de uso comum do povo", conforme o artigo 225 da Constituição Federal, quando se concretiza, afeta uma pluralidade difusa de vítimas, sendo a indenização destinada a um fundo, ao passo que o dano ambiental 
privado, o direito à indenização é direcionado a recompor o patrimônio individual das vítimas.

Ressalta-se que o dever jurídico de proteger o meio ambiente é de toda a coletividade, podendo ser exercido pelos cidadãos, pelas associações, pelo Ministério Público ou pelo próprio Estado contra o proprietário dos bens ambientais que sejam propriedades de alguém.

Verifica-se que o dano ambiental, quando se concretiza, deve ser reparado (Papel da Responsabilidade Civil). Contudo o dever de reparar o dano em matéria ambiental é bastante complexo.

Para Paulo Afonso Leme Machado, o sentido do termo "reparar" está diretamente ligado ao de "reconstituição da integridade e da funcionalidade de um objeto".(2000, p. 335).

A propósito destas questões, Paulo Afonso Leme Machado, utilizando-se dos dizeres de Francisco José Marques Sampaio, pondera que;

não é apenas à agressão à natureza que deve ser objeto de reparação, mas a privação, imposta à coletividade, do equilíbrio ecológico, do bem-estar e da qualidade de vida que aquele recurso ambiental proporciona, em conjunto com os demais. Desse modo, a reparação do dano ambiental deve compreender, também, o período em que a coletividade ficará privada daquele bem e dos efeitos benéficos que ele produzirá por si mesmo e em decorrência de sua interação. Se a recomposição integral do equilíbrio ecológico, com a reposição da situação anterior ao dano, depender, pelas leis da natureza, de lapso de tempo prolongado, a coletividade terá direito subjetivo a ser indenizada pelo período que mediar entre a ocorrência do dano e a integral reposição da situação anterior (2000, p. 335).

Desse modo, conforme se observa a tarefa de compreender o que caracteriza o dano ambiental e o dever de repará-lo exigem do aplicador do direito interpretação coerente, virado, sempre, às circunstâncias do caso concreto.

Nesta linha de pensamento, o esforço de caracterizar o dano ambiental, tem como fundamento o dever de indenização (Papel da Responsabilidade Civil).

Neste contexto, cita-se as palavras do jurista alemão Karl Larenz,

o fundamento do dever de indenizar reside na exigência de uma justiça comutativa de que aquele que tem defendido seu interesse em detrimento do direito alheio, conquanto de maneira autorizada, tem de indenizar o prejudicado, que deve suportar a perturbação do seu direito. (Nelson Nery Jr., Rosa M. Nery, apud Karl Larenz, (1994, p. 278). 
Diante disto, mesmo despendendo de todos os esforços na busca de se caracterizar o que vem a ser dano ambiental, bem como o dever de repará-lo, este se torna insuficiente, tendo em vista a complexidade que envolve o estudo em questão.

Primeiramente, quando se trata de indenização, não importa o valor estimado, este é sempre insuficiente, tendo em vista que a consumação da lesão ambiental é quase sempre irreparável. Ademais, o dano ambiental é de difícil valoração. Ou seja, nem sempre é possível ser mensurado.

Contudo é importante lembrar-se que o fundamento do Direito Ambiental é exercer sua função protetora para as presentes e futuras gerações, que é um dos seus principais aspectos.

\section{DA RESPONSABILIDADE CIVIL E O DIREITO AMBIENTAL}

Toda e qualquer ação humana resulta em impacto sobre o meio ambiente, o qual deve ser minimizado na equação custo-benefício, visando o desenvolvimento da sociedade de forma sustentável, social e economicamente equilibrada.

Vale ressaltar-se que o apelo à sustentabilidade versus danos ambientais não se trata de uma obrigação condicionada ao caráter filantrópico e econômico de um eixo comercial e de marketing, mas tão somente a um dever-ser de qualquer setor, organismos ou facção social (Savitz e Weber, 2007, p. 28 e p. 65).

A Constituição Federal de 1988, em seu artigo 225, $§ 2^{\circ}$, determina: "aquele que explorar recursos minerais fica obrigado a recuperar o meio ambiente degradado, de acordo com a solução técnica exigida pelo órgão público competente, na forma da lei." O $\S 3^{\circ}$ acrescenta: "as condutas e atividades consideradas lesivas ao meio ambiente sujeitarão os infratores, pessoas físicas ou jurídicas, a sanções penais e administrativas, independentemente da obrigação de reparar o dano."

Para Antunes (2005), as sanções determinam um caráter punitivo e educativo, ao obrigar a reparação do dano, em busca da recomposição do prejuízo causado ao meio ambiente e às vítimas, e principalmente à prevenção de casos semelhantes que possam emergir pela repetição e, novamente, causar novos danos ambientais. 
Há reparação do dano ambiental por meio de recuperação natural ou pela via da compensação pecuniária, inclusive com a possibilidade da obtenção de lucros cessantes.

O artigo 14, § 1르, Lei 6938/81 (Lei da Política Nacional do Meio Ambiente), o qual reitera pela responsabilidade civil objetiva - do poluidor, obrigado, independentemente da existência de culpa, a indenizar ou reparar os danos causados ao meio ambiente e a terceiros, afetados por sua atividade (DIAS, 1954, p. 52).

Sem obstar a aplicação das penalidades neste artigo, é o poluidor obrigado, independentemente da existência da culpa, a indenizar ou a reparar os danos causados ao meio ambiente e a terceiros, afetados por sua atividade.

O artigo 927 do Código Civil prevê expressamente a possibilidade de reparação independente da verificação da culpa.

Artigo 927 (...). Parágrafo único: "Haverá obrigação de reparar o dano, independentemente da culpa, nos casos especificados em lei, ou quando a atividade normalmente desenvolvida pelo autor do dano implicar, por sua natureza, riscos para o direito de outrem".

A teoria do Risco Integral é o entendimento majoritário no Direito Contemporâneo naquilo que concerne à Responsabilidade decorrente do Dano Ambiental.

Em matéria de direito ambiental, a responsabilidade é objetiva, orientando-se pela teoria do risco integral, segundo a qual quem exerce uma atividade da qual venha ou pretende fruir um benefício tem que suportar os riscos dos prejuízos causados pela atividade, independentemente da culpa. Com sua atividade, ele torna possível a ocorrência do dano (potencialmente danosa). Fala-se em risco criado, responsabilizando o sujeito pelo fato de desenvolver uma atividade que implique em risco para alguém, mesmo que aja dentro da mais absoluta normalidade (ROCHA, 2000, p.140).

A responsabilidade civil do causador do dano ambiental, em síntese, se enquadra na responsabilidade objetiva derivada de uma ação positiva ou negativa, com resultado lesivo e nexo de causalidade meramente etiológico, para manter o elo do agente ao dano, independente de culpa; a possibilidade de lesão a terceiros; o afastamento da licitude da conduta como pressuposto de excludente da responsabilidade do causador do dano; a 
precípua responsabilidade do Poder Público em todas as matérias que envolvam o meio ambiente; a solidariedade passiva de todos os causadores, por ação ou omissão, pelo dano ambiental, independente da existência de ação regressiva, com o intuito de excludente de ilicitude, bem como de responsabilidade do agente.

Dessa forma, o que se avalia na atribuição da Responsabilidade pelo Dano Ambiental é dano, e não, necessariamente, a conduta do agente-poluidor ou a omissão do agente fiscalizador, causador do dano. Em regra, todos serão responsabilizados pelos efeitos irreversíveis dos danos ao Meio Ambiente, porém basta a comprovação do dano.

O ordenamento jurídico-pátrio também estabelece todos os responsáveis e as formas de reparabilidade pelo dano ambiental, bem como as suas sanções. Das relações de responsabilidade, chega-se à personalidade, pois não há como se conceber a sanção ou a indenização sem o individuo que as deva receber (BARRACHO, 2000, p. 296).

Atualmente, o que é mais debatido é a responsabilidade solidária do agente público e do causador do dano, seja por ações comissivas ou omissivas. Este último, também responde como agente fiscalizador da mantença do equilíbrio do Meio Ambiente.

Houve um avanço na adoção da Teoria do Risco Integral e na responsabilidade solidária dos agentes causadores do dano e agentes públicos.

Entretanto, o óbice é a forma de comprovação mínima desse necessário elo causal entre a atividade causadora e o próprio dano ambiental.

Mesmo com a comprovação do dano ao Meio Ambiente, verificam-se situações em que o agente está autorizado à pratica lesiva, assim desconsiderando o principal - o dano propriamente dito - pelo necessário primor técnico, comprobatório e processual para a aplicação das sanções ou mesmo com a inversão do ônus da prova, a fim de que o agente consiga comprovar que a exercida atividade não gera prejuízos ou que não praticou o ato ilícito contra o meio ambiente (FERRAZ, 2000, p.28).

O momento de produzir o meio de prova do dano ambiental deve ser real e determinante, pois dá ao julgador parâmetros adequados para indenizar 0 valor equivalente ao prejuízo causado a um bem jurídico maior (CANOTILHO, 1998, p. 49).

Entretanto, repele qualquer medida preventiva do Poder Judiciário. Em casos excepcionais e por disposição de lei, ensejam em tutelas específicas e protetivas pleiteadas pelo Parquet, como são as hipóteses da Ação Civil Pública, a qual também 
está imbuída de requisitos mínimos e exigências complexas no momento de se avaliarem a extensão e a valoração do dano ao Meio Ambiente, bem como suas sanções.

Em outros casos, são cabíveis ações de tutelas protetivas, como a Tutela Específica e a Tutela Inibitória, com caráter preventivo, sancionador e punitivo; também com requisitos taxativos, de caráter assecuratório, para a aplicação da sanção aos fins colimados na lei.

Por outro lado, também como medida alternativa para a prevenção e punição efetiva do causador-poluidor, o fundamento do artigo $4^{\circ}$ da Lei 9.605/98 prevê o instituto da desconsideração da personalidade jurídica, como forma de penetração na justa composição dos danos causados por ela e a adequada responsabilidade dos causadores do dano. Não sem olvidar do papel principal do Poder Público de preservar o meio ambiente e, por meio do poder de polícia, fiscalizar a conduta comissiva ou omissiva dos sujeitos com a imposição das devidas infrações administrativas ou judiciais.

A insurgência de medidas acautelatórias e assecuratórias de direito, principalmente da preservação ou conservação do Meio Ambiente, auxilia na contextualização do plano fático ao direito posto, porém as organizações administrativa, política, econômica e judiciária não acompanham a onda renovatória dos direitos.

A gama de princípios que norteiam a atuação do Poder Público nos procedimentos administrativos, amparados pelos princípios máximos da ampla defesa e do contraditório, já determina o esvaziamento do poder de polícia do órgão administrativo, principalmente dos agentes fiscalizadores, e, por conseguinte, da litigância habitual dos agentespoluidores na certeza da impunibilidade, até findar a via judicial.

Há contrasenso no próprio texto da lei que qualifica os agentes-poluidores ou tipificam Crimes Ambientais causados pela Pessoa Física ou Jurídica (Artigo 225, § 3ำ CF), em que ora são os agentes beneficiados ora sancionados, dependendo do deslinde dos procedimentos.

O descompasso da acepção da lei, da norma processual e dos órgãos reguladores coleciona a possibilidade de benefícios processuais, como transação penal, suspensão condicional do processo ou suspensão da pena, para a responsabilidade criminal de pessoa física que cometeu dano ambiental. 
Em contrapartida, o entendimento do Superior Tribunal de Justiça (STJ) admite a necessidade de uma maior ênfase na responsabilidade desses infratores e aceita a penalização, inclusive da responsabilidade da pessoa jurídica, desde que comprovada a origem da delegação ou ordem para a execução do ato pelo seu representante legal e haja tão somente em beneficio econômico para a sua empresa.

Diante do exposto, o sistema legislativo e processual, abarcando a complexidade de normas jurídicas e mecanismos garantísticos de tutelas ambientais não enseja no cumprimento das leis que tutelam o meio ambiente.

O mero cumprimento da lei e seus regramentos, bem como de suas sanções são postergados no rito processual, para findar no cotejo de uma irreversão do dano ambiental.

São esclarecedores essas constatações, porque indicam, apenas e tão somente, o efeito de cunho programático dos institutos jurídicos e instrumentos processuais, os quais são totalmente insuficientes para promover a devida proteção do meio ambiente.

Urge desenvolver-se a construção da consciência ecológica incrementando a educação ambiental, e, por conseguinte, a reforma do sistema complexo da rede de direito material e processual para o pleito ambiental.

\section{CONCLUSÃo}

O tema relacionado com os problemas de definição do "dano ambiental", bem como a interpretação jurídica do dever de repará-lo, pode ser apreciado de diferentes formas, exigindo do aplicador do direito, interpretação coerente, sempre virado às circunstâncias do caso concreto.

A figura dos instrumentos jurídicos apresenta-se como um dos problemas mais expressivos em matéria de direito ambiental, pelo fato de caracterizar-se como um direito relativamente recente, ainda merece novos contornos jurídicos devido as constantes transformações humanas, sociais e econômicas, que sempre resultam em impacto sobre o meio ambiente.

Não se pode negar que novas e muitas perspectivas foram abertas no campo jurídico para a proteção do meio ambiente, destaca-se por apresentar um novo 
paradigma, a Constituição Federal de 1988, que acolheu em seu texto um dos mais modernos, inéditos e abrangentes conjuntos de normas de proteção ao meio ambiente, alicerçando o direito ao ambiente ecologicamente equilibrado como direito de todos, bem de uso comum do povo e essencial à qualidade de vida.

A lei $n^{\circ} 6.938$, de 31 de agosto de 1981, que instituiu a política nacional do meio ambiente, também foi um divisor de águas, introduzindo novas perspectivas de responsabilização por danos ambientais, reconhecendo ao poder público o dever de proteger, defender e preservar o meio ambiente.

Contudo, apesar dos avanços experimentados em matéria de legislação ambiental, esses ainda são insuficientes para promover a devida proteção do meio ambiente. Assim, espera-se que a construção da consciência ecológica, desperte em atitudes que vão reverberar na proteção e preservação ambiental, viabilizando o desenvolvimento sustentável.

\section{REFERÊNCIAS}

ANTUNES, Paulo de Bessa. Direito ambiental. Rio de Janeiro: Lumen Juris, 2005.

BARRACHO, J. A. O. Responsabilidade Civil por Dano ao Meio Ambiente. Editora Del Rey, Belo Horizonte, 2000.

CANOTILHO, José Joaquim Gomes. Introdução ao Direito do ambiente. Lisboa, Universidade Aberta, 1998.

DELGADO, José Augusto. Reflexões sobre o direito ambiental e competência municipal. Cidadania e Justiça. ํำ 9, v.4, 2000.

DIAS, José de Aguiar. Da Responsabilide Civil. Rio de Janeiro, Forense, v. I, 1954, p. 52).

FERRAZ, Sérgio. Responsabilidade Civil por Dano Ecológico. Revista de Direito Público, São Paulo, v.49,n.50

FENKER, E. A.(a) Análise custo-benefício aplicável ao meio-ambiente. Disponível em:<http://www.ambientebrasil.com.br/noticias/index.php3?action=ler\&id=24988>. Acesso em:02/09/2007. 
KRELL, Andreas Joachim. Concretização do dano ambiental. Objeções à teoria do "risco integral". (http://jus.com.br/revista/doutrina/texto.asp?id=1720) Acesso em 07 abr. 2002.

LOPES, José Maria de Serpa. Curso de Direito Civil. Rio de Janeiro: Freitas Bastos, 1995.

MACHADO, Paulo Affonso Leme. Direito ambiental brasileiro. 9a ed. São Paulo: Malheiros Editores, 2000.

MILARÉ, Édis. Direito do ambiente: doutrina, jurisprudência, glossário. São Paulo: Ed. Revista dos Tribunais, 2000.

NERY JR., Nelson; NERY, Rosa M. de Andrade. Responsabilidade Civil, Meio Ambiente e Ação Coletiva/ Benjamin, A. Herman (coordenador) 1994.

KRELL, Andreas Joachim. Concretização do dano ambiental. Objeções à teoria do "risco integral". (http://jus.com.br/revista/doutrina/texto.asp?id=1720) Acesso em 07 abr. 2002. p. 3.

PADILHA, Norma Sueli. Fundamentos constitucionais do direito ambiental brasileiro. Rio de Janeiro: Elsevier, 2010.

ROCHA, Julio Cesar de Sá da Rocha. Direito Ambiental e Meio Ambiente do Trabalho. Dano, Prevenção e Proteção Jurídica. Editora LTr, 1997.

SALOMON, Fernando Baum. Enfoques Variados de Direito Ambiental/ Bruno Campos Silva (organizador). São Paulo: 2004. In: O Princípio da Precaução Frente ao Nexo de Causalidade Ambiental.

SILVA, José Afonso da. Direito Ambiental Constitucional. São Paulo: Malheiros, 1995. 